\title{
LA OCUPACIÓN DEL PACÍFICO SUR COSTARRICENSE POR PARTE DE LA COMPAÑÍA BANANERA (1938-1984)
}

MSc Antoni Royo - royasp@yahoo.com

El artículo pretende esbozar la historia de la ocupación humana y económica de la región del Pacífico sur costarricense desde la llegada de los primeros pobladores sobre los que existen fuentes, hasta la implantación y posterior desarrollo de actividades de explotación bananera por parte de la Compañía Bananera de Costa Rica, filial de la United Fruit Company. La Compañía Bananera vendrá a insertarse a una dinámica poblacional y económica preexistente que condicionará sus estrategias de implantación. Por su parte, la voluntad estatal de arraigar la Compañía al país mediante los Contratos Bananeros se inscribe en el diseño institucional de poblar $\mathrm{y}$ desenclavar económicamente la Zona Sur costarricense. Por último se analiza la estructura operativa de la Compañía y se abordan brevemente las razones que motivaron el cese de operaciones así como sus repercusiones actuales.

\section{Población y sistemas productivos antes de los años 1930}

En el poblamiento y ocupación contemporáneos del territorio de la región del Pacífico sur costarricense intervienen dos corrientes. Por una parte una corriente migratoria procedente de la región de Chiriquí en Panamá de la cual tenemos constancia desde 1848 (García 1988: 33) y otra corriente desde la Meseta Central costarricense desde finales del siglo XIX (Cerdas 1993: 119). El por qué ambos grupos de población confluyen en la misma zona se explica por la diferente naturaleza de los frentes de colonización, motivados en parte por la orografía del territorio, la estructura productiva de la tierra y la presión demográfica.

Las tendencias de los frentes de colonización espontánea costarricense, una vez rebasados los pasos de salida del Valle Central, eran de buscar la bajura (Sandner 1963: 38). El movimiento se había iniciado en el siglo XIX desde la Meseta Central a partir de Desamparados hacia Acosta, Dota y Tarrazú, y desde Escazú y Ciudad Colón hasta Tabarcia y Puriscal. A medida que las tierras se agotaban y se mejoraban las comunicaciones, el frente pionero se fue trasladando hacia el sur en dos direcciones: hacia la costa del Pacífico por Aguirre y Parrita, y hacia Buenos Aires y Coto Brus, siguiendo el Valle del General (Véase figura 1). La población inmigrante procedía de la periferia de la Meseta Central, a la que se sumaron campesinos del área costera de Guanacaste y Puntarenas, de donde venían expulsados como consecuencia de la expansión de la actividad ganadera extensiva.

Por su parte, en la provincia colombiana de Panamá, los frentes colonizadores no superaron las cimas de la cordillera central hacia la vertiente del Caribe y permanecieron en la vertiente del Pacífico. Cuando se agotó esta posibilidad los colonos se desplazaron hacia el oeste, en los límites de Costa Rica (Sandner 1963: 39). Se trataba del territorio natural de chiricanos e indígenas guaymíes, al amparo de una soberanía difusa sobre una frontera que no fue definitiva sino hasta 1944.

Hacia 1849-50, las autoridades costarricenses aprovecharon para establecer su jurisdicción efectiva sobre la zona mediante la creación de la Jefatura Política de Golfo Dulce. Seguidamente, con el objetivo de poblar el territorio y afianzar su soberanía, en 1849, el Estado ideó un proyecto de colonización con familias francesas -alrededor de mil personas- para ocupar la mitad sureste de la Península de Osa. Dicho proyecto no se 
materializó (García 1988: 34), por lo que el proceso colonizador continuó vinculado a la llegada de chiricanos y "cartagos".

En 1910 un censo realizado en la región da 2.424 habitantes y en 1914 se crea el cantón de Osa con cabecera en Buenos Aires incluyendo El Pozo. Hacia 1920 ya existían los caseríos de El Tigre, El Sándalo, Agujas, Rincón, La Palma, Uvita, Dominical, Las Esquinas, Ojo de Agua y Golfito (Cerdas 1993: 119 y García 1988: 35).

Por su parte, la presencia indígena en el Pacífico sur se divide esencialmente en pueblos térrabas y guaymíes. Los térrabas se hallaban esparcidos en caseríos: Conte, Boruca, Térraba, Palmar, también llamado Palmar de los Indios (Cerdas 1993: 130).

Las primeras migraciones guaymíes documentadas procedentes de Panamá datan de los años 1920, siendo la comunidad de Abrojos-Montezuma, cercana de Altos de San Antonio en Ciudad Neily, la primera en ser establecida en territorio costarricense.

A partir de 1903, con la construcción del canal de Panamá, se impulsó la expansión de las haciendas ganaderas situadas en pleno territorio guaymí. Los indígenas eran desposeídos de sus tierras y ante la falta de tierras libres se dirigían hacia Costa Rica. Estas migraciones se enmarcaban en la tradicional transhumancia que los guaymíes practicaban entre los territorios a ambos lados de la frontera (Camacho 1996: 63).

Las actividades económicas se limitaban a la agricultura de subsistencia basada en el cultivo de granos básicos, árboles frutales, la cría de animales (aves de corral, cerdos y ganado vacuno), la caza y la pesca. En la zona se producía carne de res seca, manteca de cerdo y aceite de coco que se llevaba al mercado de Puntarenas por medio de barcos de vela en viajes largos y arriesgados (García 1988: 36).

El volumen de las actividades productivas justificaba los trabajos de infraestructura. En 1914 se aprobó la construcción de dos bodegas para granos, una en Uvita y otra en El Pozo y un beneficio de arroz en El Pozo (Cerdas 1993: 119 y 121).

Además, desde los años 1920 se desarrollaba el cultivo de banano por parte de pequeños y medianos productores. En 1925 se celebró un contrato entre el gobierno de Costa Rica y la Pirris Farm \& Trading Company propiedad de Agathon Lutz Stiegle donde se le autorizó a explotar el cultivo del banano en una extensión de 500 hectáreas a unas 75 millas al sur de Puntarenas, aproximadamente en las llanuras del río Parrita (Kepner 1949: 88). En 1930 exportó 19.000 racimos, 72.000 en 1931 y 157.000 durante los seis primeros meses de 1932. En 1927 contaba con unos 85 - 90 empleados y en agosto de 1930 explotaba más de 900 hectáreas de banano. Progresivamente el cultivo se fue extendiendo por las riberas de los ríos Parrita, Naranjo, Sierpe, Grande de Térraba y por Puerto Jiménez. Además de la Pirris Farm \& Trading Co. dirigida por Agathon Lutz, existían otras compañías de productores independientes como las de Fabio Calvo, Saborío y Ulloa, etc (Cerdas 1993: 121-122).

Así, contrariamente a la visión geográfica tradicional ${ }^{2}$, la región del Pacífico Sur costarricense, antes de la llegada de la Compañía Bananera, ya se hallaba humanizada y bajo explotación económica con cultivos de arroz, banano y granos.

\footnotetext{
${ }^{1}$ Término popular que designa a los naturales del Valle Central de Costa Rica.

${ }^{2}$ Hall, Carolyn "Costa Rica, una interpretación geográfica con perspectiva histórica" San José: Editorial Costa Rica, 1984, p. 169 citando a Jeffrey Cassey ("Limón 1880-1940. Un estudio de la industria bananera en Costa Rica" San José: Editorial Costa Rica, 1979, pp.43-46) redunda en la idea que "el contrato Cortés-Chittenden (...) permitió a la compañía desarrollar nuevos enclaves de plantaciones en tierras vírgenes en los valles de Parrita, Térraba y Coto Colorado". Por su parte, Sandner "La colonización agrícola de Costa Rica" San José: Instituto Geográfico Nacional, Tomo I, 1964, p. 82, afirma: "La bajura Sureste de Costa Rica estaba casi despoblada cuando la Compañía Bananera inició sus actividades".
} 


\section{El fomento estatal a la ocupación territorial}

Durante todo el siglo XIX y hasta bien entrado el siglo XX, existió la percepción estatal de que la abundancia de tierras y la escasez de brazos para trabajarlas frenaba el progreso económico del país. Por ello los gobiernos se preocuparon en fomentar la producción agrícola en base a la incorporación al espacio nacional de tierras cultivadas.

El ideario liberal en cuanto a la política agraria se basaba en fomentar la producción agraria y el cambio técnico, poblar, comunicar y desde los años 1870, cuando el café decae, atraer capitales y diversificar la producción (Viales 2000: 82).

La misma coherencia de la política liberal "explica la concesión ferrocarrilera y posteriormente las prebendas bananeras, éstas últimas no deben interpretarse como una consecuencia indirecta del cultivo cafetalero, sino más bien como una consecuencia directa de la política de diversificación agrícola defendida por los liberales" (Viales 2000: 359-360).

Al igual que el café en su momento, el banano fue factor de expansión de la frontera agrícola y de la ocupación sistemática del espacio: "El deseo de abrir nuevas tierras para la producción del café y el banano era una fuerza motora detrás de la colonización agrícola después de la independencia (Hall 1984: 112)"

En este sentido, sostenemos que los contratos bananeros de los años 1930 emanan de esta concepción, de la misma manera que el fácil acceso a la tierra que sólo se trunca con el fin de la frontera agrícola a mediados de los años 1960, es un resabio de las políticas liberales de favorecer la ocupación y población del territorio.

Hubo tres contratos entre el gobierno y la UFCo en los años 1930. La Ley-Contrato de 1930 es la continuación de la Ley de 1910. Hasta 1910, cuando se acordó gravar con un centavo por racimo de banano exportado, las exportaciones de banano no pagaban impuestos en Costa Rica. Según la Ley nº 82 del 29 de octubre de 1910, el impuesto aplicaría por un período de veinte años y el Estado se comprometía en no añadir otro tipo de gravamen durante el período (Kepner 1949: 83). Desde 1927 la UFCo. fue reduciendo su nivel de actividad reflejado en la disminución del área plantada -de 7.100 hectáreas en 1924 pasó a 5.100 en 1929-. En agosto de 1929, la Asamblea Legislativa costarricense aprobó una ley gravando el racimo de banano proporcionalmente al volumen total exportado, estableciéndose el impuesto de 3 a 5 dólares por racimo (Carcanholo 1978: 159). Sin embargo la UFCo. no la aceptó y el gobierno propuso otro contrato -ante el temor de que la Compañía abandonara actividades y se trasladara a Honduras donde no había impuesto-, votado el 30 de agosto de 1930 donde se gravaba el racimo con dos centavos de dólar por un período de veinte años, sin que hubiera otro tipo de gravamen. Dicho contrato regiría por 20 años, hasta el 29 de octubre de 1950.

En contrapartida, mediante el Contrato-Ley $\mathrm{N}^{\circ} 3$ de 1930, la UFCo. se comprometió en expandir las actividades bananeras sembrando 3.000 hectáreas de nuevas tierras con bananos, de las que un $50 \%$ por lo menos se haría en el Atlántico, además, debía incorporar contratos de compra con productores locales que significaran 3.000 hectáreas nuevas de plantación en la región atlántica.

En su estrategia de capear la crisis económica y desplazar las actividades al Pacífico, la UFCo. firmó el contrato de 1930, pero ni dio mantenimiento a las plantaciones existentes, ni sembró plantaciones nuevas: "de las tres mil hectáreas se han sembrado solamente doscientas treinta y ocho y media al cabo de dos años" y se negó a renovar los contratos con productores contratistas (Carcanholo 1978: 165).

Como represalia, el Congreso Nacional propuso excluir del contrato de 1934 la zona del Pacífico y la Compañía reaccionó amenazando con limitar sus inversiones en el Atlántico a $\$ 100.000$ : “(...) la Compañía no podría asumir la obligación de contratar 
más de tres mil hectáreas a 0,5 c. moneda de los Estados Unidos por racimo computado en el Atlántico, tampoco podría obligarse a prestar más de \$100.000 en esta zona."3

El contrato de 1934 surgió para enmendar los incumplimientos del contrato de 1930 y estableció que la Compañía debía cubrir mediante contratos 3.000 hectáreas de cultivo de banano en cada vertiente del país. El plazo era de dos años y medio para el Atlántico y tres años y medio para el Pacífico, de no cumplir la compañía se comprometía en plantar la extensión total por su propia cuenta en un plazo de cuatro años:

"Las 3.000 hectáreas del Pacífico se escogerán de terrenos cuya altura sea menor de 300 metros sobre el nivel del mar y dentro de un radio de 25 kilómetros de la línea principal del ferrocarril al Pacífico o del litoral del golfo de Nicoya, abarcando también una faja de 25 kilómetros de ancho, a la orilla del mar que corra hacia el Sur, entre la Punta Herradura y el distrito recorrido por el río Naranjo" 4 .

Sin embargo los productores particulares sólo contaban con un periodo entre un año y medio y dos años y medio a partir de 1934 para iniciar nuevos cultivos. Este trato de favor permitía a la compañía demorar la plantación mientras el mercado bananero del mundo no mejorara de condición (Kepner 1949: 275).

Por último el contrato de 1938, conocido como Cortés-Chittenden por sus firmantes ${ }^{5}$, establecía la construcción de puertos de altura en Quepos y Golfito y la obligación de "sembrar bananos en terrenos de su propiedad o de particulares que ella misma escogerá en la región del Pacífico, en una extensión mínima de cuatro mil hectáreas ","

En la práctica, a pesar de que estas reglamentaciones buscaban asegurar la independencia de los productores locales, se dio un proceso de absorción de éstos por parte de la Compañía Bananera ya que ésta escogía los contratistas, les otorgaba créditos o les renovaba los contratos según su conveniencia.

\section{Las estrategias de implantación de la Compañía Bananera}

La relación de ocupación y explotación que estableció la UFCo en las tierras bajas del Pacífico costarricense mantiene similitudes y diferencias con la desarrollada medio siglo antes en las plantaciones bananeras del Caribe.

Sin embargo, a diferencia de las llanuras costaneras del Caribe, las planas fluviales de la vertiente del Pacífico se hallaban en gran parte humanizadas y con cultivos en pleno rendimiento. Esto determinó el carácter a menudo fraudulento del proceso de acaparamiento de las tierras con mejores condiciones agroecológicas para el cultivo del banano en la región pacífica.

A partir de los años 1920 la producción del banano en las plantaciones del Atlántico decae por diversos factores (Viales 2000: 50) entre los que destacan el agotamiento de los suelos y la enfermedad de Panamá o "sigatoka negra"7. Paralelamente, desde 1922 la UFCo. había iniciado investigaciones sobre calidad de suelos en la región de Golfo Dulce (Lewis 1982: 126).

\footnotetext{
${ }^{3}$ Memorandum de G.P. Chittenden a la Comisión de Hacienda del Congreso Nacional, Limón, 26 de septiembre de 1934. Colección de Leyes de Costa Rica, año 1934, Imprenta Nacional, San José, 1935, p. 489.

${ }_{5}^{4}$ Decreto-Ley № 30 de 10 de diciembre de 1934 . Artículo $1^{\circ}$, cláusula segunda.

${ }^{5}$ León Cortés, presidente de Costa Rica y George Peters Chittenden, apoderado generalísimo de la Compañía Bananera de Costa Rica.

${ }^{6}$ Ley $n^{\circ} 133$ de 23 de julio de 1938, Gaceta n¹65 de 24 de julio de 1938 en Compañía Bananera de Costa Rica, Chiriquí Land Company, United Fruit Company "Leyes, contratos y resoluciones relativas a las industrias de banano, abacá, cacao y palma africana oleaginosa. 1930-1953", p. 33.

${ }^{7}$ La sigatoka negra es una enfermedad en la hoja del banano que causa disminución en el área de la hoja, maduración prematura del fruto y pérdidas de hasta el $50 \%$ de los cultivos. Ploetz, Randy "The most important disease of a most important fruit, Black sigatoka of banana". http://www.apsnet.org/education/feature/banana/Top.html
} 
La UFCo. decidió trasladar sus actividades al Pacífico en una medida que consistía en mudarse por cuanto los precios de la tierra eran más bajos que rehabilitar zonas afectadas por enfermedades.

Como señala Jones, esta estrategia se inscribe en las prácticas tradicionales de la Compañía: " (...) in its operations in the Caribbean Lowlands the United Fruit Company was early forced to adopt a policy of regular abandonment of old fields and planting of new ones. This policy was possible only because of the large area of suitable virgin land available under contract agreement to the company" (Jones 1952: 5)

Las zonas bananeras en América Central se suelen situar en las planicies aluviales de los valles cruzados por grandes ríos, en lugares escogidos por el drenaje potencial de su suelo. En la franja costera correspondiente al Pacífico costarricense, la Compañía Bananera de Costa Rica $^{8}$ no siguió un único patrón de ocupación y explotación sino que discriminó en función de la existencia de pobladores y productores de banano.

Podemos distinguir tres regiones donde se implantó la Compañía Bananera de Costa Rica en la vertiente del Pacífico: (Véase Figura 2)

-Los valles de los ríos Parrita, Damas, Naranjo y Savegre en el Pacífico Central que conformaron la División de Quepos.

-El delta abanico del río Térraba y el valle falla del río Esquinas entre Palmar y Golfito en el Pacífico sur que formó la División de Golfito.

-El valle de Coto Colorado fronterizo con Panamá que fue adscrito a la División de Armuelles en Panamá.

\section{El Pacífico central}

En el contexto de la crisis de 1929 y el avance de la enfermedad de Panamá en las plantaciones del Caribe, el menor costo para la UFCo era absorber a los productores locales de banano del Pacífico central y continuar comprando tierras en el Pacífico sur a la espera de que la situación económica mejorara y poder ponerlas a producir.

El interés de la compañía no era tanto plantar en tierras propias sino más bien apropiarse de las tierras de los productores locales y de las mejores tierras para el cultivo del banano en el Pacífico para así bloquear la entrada de competidores. Por lo demás, las altas inversiones requeridas para la construcción de infraestructuras y el control de la propagación de enfermedades estaban fuera del alcance de eventuales competidores nacionales.

En 1935 la Compañía Bananera adquirió el control de la Pirris Farm \& Trading Company iniciando la explotación bananera y el monopolio de facto en el Pacífico. Progresivamente los diferentes contratistas serán englutidos por la Compañía quien será la única en fijar los precios de compra. En 1942 sólo el 6\% del área de cultivo del banano en la zona del Pacífico central permanecía en manos de productores privados (Cerdas 1993: 136).

A partir del gráfico siguiente podemos inferir el origen de la producción de banano en la región del Pacífico. Si tomamos 1936 como fecha de inicio de la explotación bananera de la Compañía en el Pacífico en tierras propias tras la absorción de la Pirris Farm \& Trading Company, se constata como desde 1937 la Compañía exporta el banano producido en sus fincas del Pacífico por su puerto de Limón (1) y que los embarques por el puerto de Puntarenas (4) disminuyen hasta desaparecer en 1940.

Entre 1930 y 1939 los embarques de banano por el puerto de Puntarenas (4) correspondían a productores privados. Tras la puesta en funcionamiento del muelle de

\footnotetext{
${ }^{8}$ Para protegerse de la Ley Antimonopolio estadounidense, la UFCo se ve obligada a crear una subsidiaria en Costa Rica. El 19 de septiembre de 1930 con la formación de la Compañía Bananera de Costa Rica, se inicia el traslado de operaciones hacia el Pacífico costarricense.
} 
Quepos (5) en 1939 no se puede saber la proporción de banano en manos de productores privados ya que por dicho puerto tanto podían embarcar banano la Compañía como los cultivadores privados independientes.

Desde 1937 la producción bananera en el Pacífico comienza a ser significativa y en 1940 supera a la producción en fincas del Atlántico. En 1940 el banano producido en el Pacífico totalizaba 1.857.000 racimos mientras que en el Atlántico se cultivaron 1.437 .000 racimos.

Con la puesta en servicio del muelle de Quepos, 1939 es el último año en que se exporta fruta producida en el Pacífico por el puerto de Limón. En adelante el muelle de Quepos competirá con el muelle de Golfito por el que será superado en cuanto a volumen de racimos de banano exportados desde 1945.

Finalmente, entre 1941 y 1946 disminuyeron los embarques de banano desde el puerto de Quepos debido al abandono de tierras provocado por la "sigatoka negra" y la estrategia de desplazamiento de los cultivos de banano hacia el Pacífico sur, además de la escasez de barcos como consecuencia de la segunda guerra mundial.

Gráfico 1: Exportación de banano por puerto de embarque, 1930-1948

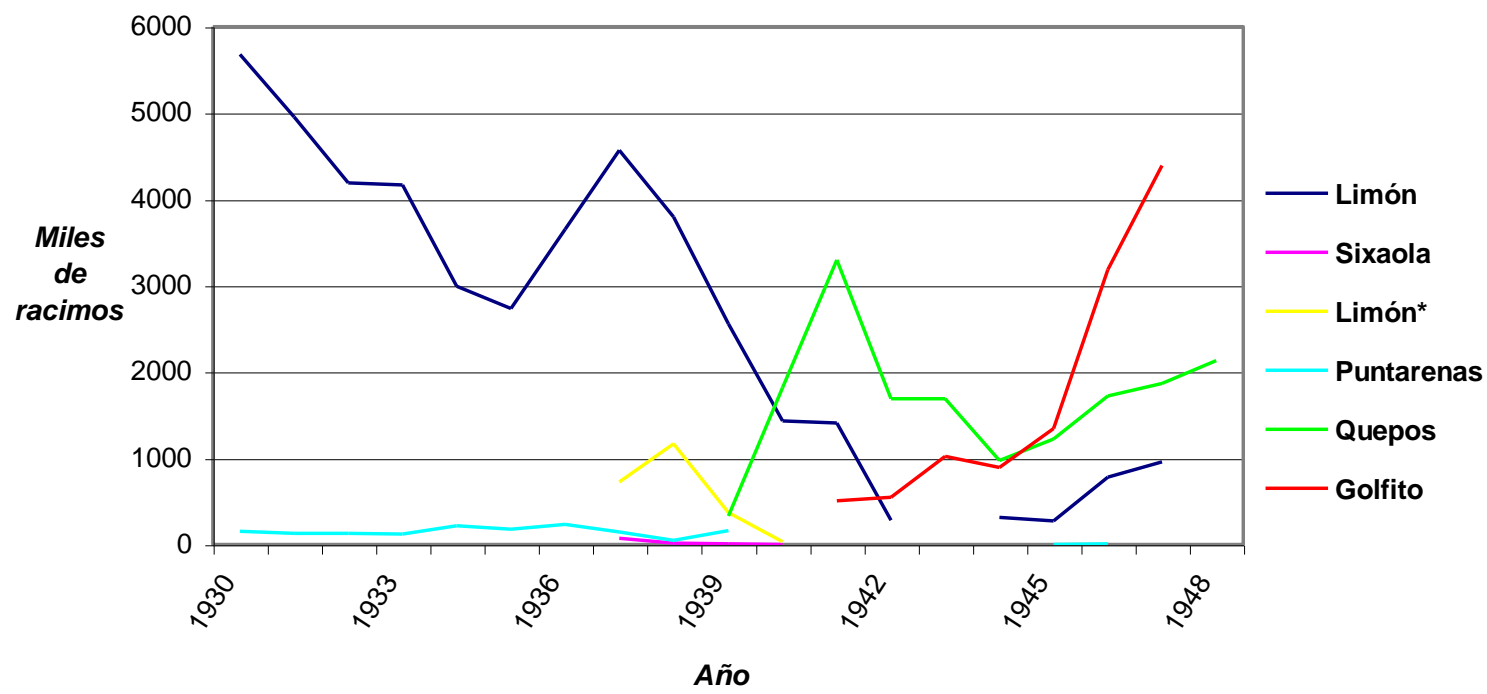

* Banano producido en el Pacífico pero embarcado por Limón

Fuente: Elaboración propia en base a Carcanholo, Reinaldo "Sobre la evolución de las actividades en Costa Rica” Estudios Sociales Centroamericanos n¹9, 1978, pp.167, 174 y 175.

\section{El Pacífico sur}

En la región del Pacífico sur, los métodos para el acaparamiento de tierras variaron de los puestos en práctica en el Pacífico central.

En su estrategia de implantación, la UFCo desde los años 1920 venía realizando un proceso de compra de tierras por terceros a través de la Golfo Dulce Land Company, compañía pantalla fundada por Fernando Castro, latifundista puntarenense y socio de la UFCO (Kepner 1949: 90). El proceso no estuvo exento de irregularidades en la medida en que las zonas de mayor aptitud agroecológica para el cultivo del banano (planas fluviales) ya estaban ocupadas. La apropiación por parte de la Golfo Dulce hacia 1927, por medio de denuncios de baldíos $^{9}$ de unas 9.500 hectáreas que incluían las

\footnotetext{
9 "Son terrenos baldíos todos los comprendidos en los límites de la República, que no pertenecen con título legítimo a los particulares. Los terrenos baldíos, ya estén situados en las islas, ya en tierra firme, pertenecen al Estado". Código Fiscal de 1885, párrafo XIV, art. 508 en Sandner “La colonización ...", Tomo I, p. 152.
} 
poblaciones de El Pozo, Ojo de Agua, Balsar y Palmar- poblada esta última por indígenas- constituye el paradigma de esta política. Entre los afectados, 63 propietarios de 2.304,26 hectáreas expropiadas por la Golfo Dulce pidieron la intervención del Gobierno pero acabaron perdiendo sus tierras (Cerdas 1993: 129)..

Otro mecanismo de acaparamiento de tierras fue la Ley de Gracias que permitía a las municipalidades vender derechos de denuncios de baldíos nacionales. Fue así como la Golfo Dulce Land Company obtuvo 73.000 hectáreas en los márgenes de los ríos Grande de Térraba y Sierpe. Esta venta contravenía la ley que impedía enajenar la milla marítima y fluvial (en ríos navegables) pero a pesar de las pruebas de navegabilidad de dichos ríos, el fallo judicial favoreció los intereses de la Golfo Dulce (Cerdas 1993: 128-133).

El Estado desoyó las voces de protesta que generaba tal irregular concentración de tierras ${ }^{10}$, su estrategia era fijar la UFCo en el país en un momento en que otros países competían con Costa Rica para ofrecer mejores condiciones (Carcanholo 1978: 158159). Por otra parte entendía continuar con la política de diversificación agrícola así como poblar y ocupar el Pacífico sur máxime en un momento de tensiones fronterizas con Panamá a resultas de la guerra de Coto en 1921.

\section{El valle de Coto Colorado}

La estrategia seguida por la UFCo en Panamá no difiere de la seguida en Costa Rica. En Panamá se abandonaron las plantaciones en Bocas del Toro en 1926. Entre 1923 y 1926 la UFCo. compró tierras aptas para la producción de banano en la región de Chiriquí, junto a la frontera costarricense (Ellis 1983: 69). La compañía quería utilizar el trazado del Ferrocarril Nacional de Chiriquí ${ }^{11}$-finalizado en 1927- desde el puerto de Armuelles y conformar una unidad de explotación bananera a caballo sobre la región fronteriza entre Costa Rica y Panamá. Para ello aprovechó el diferendo fronterizo que enfrentaba ambas naciones, las cuales al mismo tiempo que se enfrentaban en el plano político también se disputaban económicamente por el contrato bananero con la UFCo.

La región fronteriza que enmarca los límites meridionales entre Panamá y Costa Rica cuenta con tierras de igual topografía y clima por lo que la UFCo. las consideró como una unidad territorial sin contemplar la división político-administrativa. Se añade una delimitación imprecisa de los límites en el sector de Coto Colorado reclamado por Panamá y bajo soberanía costarricense según el Laudo White de 1914. En febrero de 1921 ambos países se enfrentaron en la guerra de Coto y por ende cesaron relaciones diplomáticas hasta 1928. La fijación de los límites fronterizos (Tratado Arias-Calderón) se hizo efectivo en 1944, coincidiendo con los proyectos de construcción del tramo de la Carretera Interamericana en dirección a Panamá.

En 1927, la Chiriquí Land Company (CHIRILANCO), subsidiaria de UFCo., obtuvo de C.W. Müller 7.000 hectáreas situadas en el valle de Coto Colorado en la zona que va de La Cuesta hasta Pueblo Nuevo de Coto (Véase Figura 2). Estas tierras fueron adquiridas al amparo de las leyes panameñas, al respecto se acusa de colusión de intereses con el Estado pues tanto la UFCo como Müller tenían el mismo abogado panameño, Harmodio

\footnotetext{
${ }^{10}$ Desde 1930 existía debate en la prensa en torno a las maniobras de la UFCo. En 1934 la Liga Progresista de El Pozo protestó ante el Congreso contra la ocupación de las tierras en la milla fluvial en los ríos Grande de Térraba y Sierpe, máxime cuando algunas áreas ya se hallaban ocupadas. Cerdas, op.cit., pp. 130-133.

${ }_{11}$ Vía férrea estatal construida en 1927. Mayor información sobre las actividades y contratos de la Chiriquí Land Company se halla en: Colectivo "Panamá y la Frutera. Análisis de una confrontación económico-fiscal" Panamá: Imprenta Universitaria, 1974. Miralles Gonzáles, Miguel "Historia humana y económica de Puerto Armuelles" Panamá: Editorial Mizrachi y Pujol, S.A., 2001, pp. 34-45.
} 
Arias, quien tras la revolución de 1931 se convirtió en presidente de Panamá (Kepner 1949: 94).

En 1927, la Chiriquí Land Company, firmó una concesión por treinta años ${ }^{12}$ con el gobierno panameño para desarrollar el cultivo del banano en la región de Chiriquí, conformándose la División de Puerto Armuelles.

En cuanto a las tierras de Müller, la incertidumbre política en la frontera retrasaba su explotación efectiva. En 1928 el abogado costarricense de Müller propuso que el gobierno de Costa Rica cediera a Panamá un sector fronterizo de alrededor 50.000 hectáreas que contenía las tierras de Müller. A pesar de que el presidente Ricardo Jiménez era favorable, la opinión pública rechazó el plan (Kepner 1949: 95) y la solución completa sólo se logró después de 1944. Las tierras de Müller conformaron el distrito de Coto Colorado y fueron explotadas en Costa Rica, pero se rigieron con las normas de operación de la División de Puerto Armuelles en Panamá adscrita a la Chiriquí Land Company hasta los años 1950. Con posterioridad el Distrito de Coto Colorado pasó bajo jurisdicción de la Compañía Bananera. Según el Contrato ${ }^{\circ} 1$ de 26 de enero de 1945, se autoriza a CHIRILANCO para exportar toda la producción bananera en territorio costarricense así como la introducción de insumos para las fincas en Costa Rica sin ningún tipo de gravamen (Colectivo 1974: 24).

En definitiva, hubo dos tipos de estrategia de ocupación territorial: en la región de Quepos-Parrita, área que contaba con cultivos de banano en explotación, la Bananera optó por la absorción de los productores independientes. En el sur, valles del río Grande de Térraba, Esquinas y Coto, zonas ocupadas aunque con menor desarrollo del cultivo del banano, la Compañía, con el aval del Estado, se hizo con las mejores tierras vulnerando en ocasiones los derechos de los poseedores legítimos.

Por último, la ocupación de la región de Coto Colorado ilustra la diferencia de miras entre los Estados que se enfrentan por nacionalizar política y económicamente sus márgenes fronterizos y la transnacional bananera cuya lógica de funcionamiento es territorial y no político-administrativa.

\section{La estructura de la operación productiva de la Compañía Bananera}

La explotación bananera de la UFCo en territorio costarricense estaba administrada bajo tres divisiones bananeras, Quepos y Golfito en Costa Rica y Puerto Armuelles en Panamá. El manejo de toda la operación bananera en Costa Rica estaba centralizado en el puerto de Golfito, donde se recibía la fruta por tren y se embarcaba rumbo a la costa Pacífica de los Estados Unidos.

La División Bananera era un subsistema autosuficiente dentro de un sistema mayor de actividades económicas de la compañía matriz (Ellis 1983: 107). Cada División integraba todas las facetas de la actividad bananera desde la producción o la compra hasta la exportación.

Jones caracteriza la organización de una finca tipo en la División de Golfito (Jones 1952: 14). La División se subdividía en Distritos, cada Distrito en superintendencias y éstas en fincas. Cada Distrito bananero estaba compuesto de entre cinco y nueve fincas, siendo siete fincas lo más usual. Cada finca era rectangular y medía 333,3 hectáreas $\left(800\right.$ acres $\left.^{13}\right)$ de las que alrededor de 8,3 hectáreas (20 acres) estaban ocupados por el

\footnotetext{
${ }^{12}$ Contrato n¹3 del 19 de julio de 1927. En 1950 el contrato se prorrogó 29 años más, su fecha final de vencimiento quedó para el 15 de marzo de 1986. El impuesto sobre las exportaciones de bananos se fijó en un centavo los primeros siete años y luego en dos centavos, mientras que en Costa Rica fue de dos centavos. Kepner, Charles y Soothill, J.H. "El imperio del banano. Las compañías bananeras contra la soberanía de las naciones del Caribe", Ediciones del Caribe, México, 1949, p. 95.

${ }^{13} 1$ acre $=0,40469$ hectáreas
} 
caserío, ubicado en un punto central de acuerdo a un plan uniforme, y 62,5 hectáreas (150 acres) por pastos destinados a alimentar a las mulas que transportaban la fruta hasta el ferrocarril.

\section{La División de Quepos (1938-1956)}

La explotación bananera en manos de productores independientes existía en el valle del Pirris desde los años 1920. Con la llegada de la Compañía Bananera, mediante la progresiva absorción de aquéllos, en especial tras la compra de la Pirris Farm and Trading Company en 1935, la población de Parrita fue la primera en desarrollarse. Hasta la inauguración del muelle de Quepos en 1938, el banano era sacado de las fincas al embarcadero de Barbural sobre el río Palo Seco y de allí mediante lanchones era transportado a Puntarenas. Posteriormente, Quepos y Parrita fueron unidos por una línea de ferrocarril de 24 kilómetros de longitud para facilitar el embarque del banano.

La División de Quepos constaba de cuatro distritos: Parrita, Damas, Naranjo y Savegre. (Véase Figura 2). La actividad bananera estuvo en expansión hasta 1953, pero desde 1941 el inicio de actividades de la división de Golfito desplazó la explotación hacia el Pacífico sur, debido en parte al progresivo declive del rendimiento de las tierras de Quepos.

Los suelos de la división de Quepos tenían expectativas de vida útil inferiores a cinco años debido a la existencia de cultivos desde los años 1920. En general se estima que los mejores suelos tienen un periodo óptimo de aprovechamiento de 25 años (Jones 1952: 11-12), por lo que la compañía empezó a plantar otros cultivos como cacao, palma africana o pastos.

En 1947 la Compañía tenía "alrededor de mil hectáreas de tierra sembradas de dicha planta (palma africana) y abriga el propósito de ampliar este experimento, siempre que pueda tener la seguridad de que no habrá un aumento en los actuales impuestos."14

Según el Contrato de 1948 la Compañía se obliga a plantar "una extensión adicional mínima de dos mil hectáreas de cacao y mil doscientas hectáreas de palma africana oleaginosa" y "a construir, dentro de los tres años siguientes a la fecha de dicha ratificación, por lo menos una planta experimental para extraer el aceite del pericarpio del corozo de dicha planta" ${ }^{215}$. El mismo contrato también especifica la obligación de siembra de 3.500 hectáreas de banano en el valle de Coto Colorado en un plazo de cinco años a partir de la fecha de ratificación del contrato. En 1950 se fundó la primera procesadora de fruta de palma en Damas, más tarde se cerró para luego crearse las de Naranjo y Palo Seco.

La División de Quepos cesó la actividad en 1956. La Compañía arguyó causas naturales, en 1953 redujo sembradíos debido a fuertes vendavales y a dos prolongadas huelgas laborales. En realidad, la Compañía prefirió concentrar la operación bananera en el Pacífico sur y dedicar las tierras de la División de Quepos al cultivo de la palma y el cacao, en una estrategia de diversificación ante el inicio de actividades en la zona Atlántica de Costa Rica de la Standard Fruit Company en 1956.

En la región de Quepos y Parrita, a finales de 1948 la Compañía poseía 1.041,6 hectáreas de cacao y cerca de 3.333,3 hectáreas de palma africana (Jones 1952: 12). Hacia 1958, May y Plaza estiman un área cultivada de 4.166,6 hectáreas de palma africana y 2.083,3 hectáreas de cacao, empleando entre 700 y 800 trabajadores (Plaza 1958: 154). En total, en la División de Quepos se explotaron alrededor de 12.000 hectáreas (Stouse 1967: 2).

\footnotetext{
${ }^{14}$ Memorando de la Compañía Bananera dirigido a la Secretaría de Hacienda previo a la aprobación del Decreto-Ley $N^{\circ} 323$, (Contrato de 1948), 7 agosto 1947. Según este contrato el Estado se compromete en no gravar la industria del cacao ni de la palma africana oleaginosa (Art.n॰3).

${ }^{15}$ Decreto-Ley № 323 de 27 de diciembre de 1948, Imprenta La Nación, San José, 1949, pp.13-14.
} 
Respecto a la mano de obra, Sandner señala que entre 1938 y 1948, llegaron a la División de Quepos alrededor de 10.000 personas (Sandner 1964: 81). Según Plaza y May, en 1947, fecha en que se lograron los máximos de exportación de racimos, trabajaban cerca de 5.600 personas (Plaza 1958: 154).

\section{La División de Golfito (1941-1984)}

La División de Golfito estaba compuesta por los distritos de Palmar Sur, Esquinas y Los Cotos (Véase Figura 3). El Distrito Coto Colorado pertenecía a la División de Puerto Armuelles de la Chiriquí Land Company, subsidiaria de la UFCo. en Panamá.

En un principio, Puerto Jiménez, en la Península de Osa, fue el centro administrativo hasta que se acondicionó Golfito debido a las ventajas de su fondeadero natural.

El Distrito Palmar, situado en el valle del río Grande de Térraba, reunía 18 fincas, numeradas del 1 al 18, cuyas superficies oscilaban entre las 333 y 500 hectáreas. También existían contratos con finqueros independientes en Sierpe (finca Las Condesas) y Pozo Norte (Finca Webb) ${ }^{16}$.

El Distrito Esquinas situado entre Palmar y Golfito en el Valle Falla del río Esquinas totalizaba cerca de 2.100 hectáreas (Jones 1952: 13) en 1948. Estaba conformado por siete fincas que llevaban el nombre de las siete provincias costarricenses.

Por último, el Distrito Los Cotos, entre Golfito y Ciudad Neily, contaba con 25 fincas, numeradas del 41 al 65. Este área se habilitó a partir del inicio de la construcción del ferrocarril entre Golfito y la frontera panameña. El ferrocarril partía del kilómetro 18 de la línea Golfito-Palmar en un lugar llamado Unión y desde allí la Compañía emprendió la hechura de 25 fincas que fueron llamadas finca 41, finca 42, etc. La finca 47, también llamada Coto 47, fue la más importante y constituyó el centro de administración regional con aeropuerto y planta térmica de electricidad.

El Distrito Coto Colorado estaba compuesto por diez fincas todas ellas bautizadas con nombres de árboles: Peral, Jobo, Mango, Laurel, Caucho, Limón, Bambito, Cenizo, Roble (o finca 12 de Panamá) y Naranjo (Véase Figura 2). La Chiriquí Land Company exportaba fruta panameña desde Puerto Armuelles pero se trataba de un puerto sin defensas naturales cosa que dificultaba el embarque de fruta, por lo que la Compañía prefería sacar la fruta por Golfito. Una vez resuelta la delimitación fronteriza, la Chiriquí Land Co. unió Puerto Armuelles con Golfito mediante la vía ferroviaria, vinculando de este modo todas las plantaciones del valle de Coto Colorado. Seguidamente, el gobierno costarricense construyó el puesto fronterizo de Puerto González Víquez donde funcionaría la Aduana y el Resguardo Fiscal.

La evolución de la División de Golfito mantuvo la misma dinámica de explotación que la División de Quepos. Siguiendo su política de abandono de viejas plantaciones, en 1955, tras unas inundaciones que ocasionaron numerosas pérdidas, la Frutera abandonó el Distrito Palmar Sur y decidió ampliar cultivos en el Distrito Esquinas, en expansión desde 1952. En 1966 se optó por el abandono del Distrito Esquinas ante el avance de la "sigatoka negra" en sus plantaciones. A pesar de conocerse la variedad Valery, más resistente a la enfermedad, la Compañía desestimó su introducción en Esquinas y escogió Palmar Sur porque la planta del banano es muy sensible al transporte y el costo de mejorar las infraestructuras (carreteras, drenajes y puentes) en Esquinas resultaba demasiado elevado.

En 1956 el volumen de tierras pertenecientes a la Compañía en Costa Rica alcanzaba las 203.526,4 hectáreas, de las que sólo mantenía bajo cultivo el 13,3\%, es decir, 27.087

\footnotetext{
${ }^{16}$ La finca Webb, situada en el margen norte del río Grande de Térraba y Puerto Cortés, contaba con 833,3 hectáreas (2.000 acres). Jones, op.cit., p.13.
} 
hectáreas ${ }^{17}$. Para 1962, Contreras señala que la Frutera poseía 27.238 hectáreas bajo cultivo por cuanto el área propiedad de la Compañía era de 67.212 hectáreas en 1974, de las que 26.595 se ubicaban en Golfito, 26.080 en Quepos y 14.537 en Limón (Contreras 1974: 253-254).

En 1979 la Compañía cultivaba en el Pacífico 24.000 hectáreas, de las que el 28,27\% (6.786 hectáreas) estaban sembradas de banano y el 59\% (14.172 hectáreas) de palma aceitera. El cultivo del banano se ubicaba en los Distritos Los Cotos (3.121 hectáreas) y Palmar Sur (3.665 hectáreas) mientras que la palma predominaba en Quepos y en menor medida en Los Cotos y Palmar (Heilbron 1979: 127).

Por su parte, en 1953 laboraban 19.891 trabajadores en las plantaciones del Pacífico, el nivel máximo para todo el periodo de operación de la Compañía (Carcanholo 1978: 182). Según datos de la Frutera, el promedio de trabajadores en las plantaciones del Pacífico en 1979 era de 6.423, $3.800(59,16 \%)$ laboraban en el banano y $2.623(40,83 \%)$ en las actividades de la palma. De ellos, 4.950 (77\%) estaban empleados en la División de Golfito y los 1.473 (23\%) restantes en las fincas de la División de Quepos (Heilbron 1979: 134).

A partir de los datos anteriores, se puede apreciar la especialización de la División de Quepos en el cultivo de la palma, por cuanto los Distritos Los Cotos y Palmar Sur producían banano y concentraban mayor volumen de mano de obra que el cultivo de la palma africana en Quepos. Así, la actividad productiva en la División de Quepos afectaba mayor volumen de tierra pero menor número de trabajadores, todo lo contrario a la División de Golfito. Por otra parte, en 1979 el Distrito Los Cotos albergaba el 46\% del área total dedicada al cultivo del banano y el Distrito Palmar Sur el restante 54\%.

En 1983 la Compañía decide abandonar 2.140 hectáreas que tenía en el Distrito Los Cotos y sustituir el cultivo del banano por el de palma africana, presente desde 1966. La medida significó el despido de 3.000 trabajadores quedando sólo 500. Como consecuencia fueron invadidas alrededor de mil hectáreas en las fincas $n^{\circ} 43,44,46,48$ y 49. En noviembre de 1984 tras una huelga laboral de tres meses, la Compañía cierra Palmar Sur, el último distrito en actividad. El abandono de 2.731 hectáreas en Palmar Sur significó el fin de las operaciones bananeras en el Pacífico sur.

En marzo de 1985 se compraron a la Compañía 1.703 hectáreas para ubicar proyectos agrícolas en el marco del programa UNESUR (Unidad Ejecutora del SUR). UNESUR era un programa de agricultura de cambio (cacao y palma africana) en donde se aprovechaba la infraestructura dejada por la Bananera y las capacidades del obrero.

Sin embargo, la United Brands ${ }^{18}$ no abandonó la zona sino sólo la producción de banano y concentró sus actividades en la producción de palma aceitera en Quepos y Coto. En 1989 la Compañía Palma Tica mantenía 7.000 hectáreas cultivadas con palma aceitera en Coto 47 y 275 hectáreas en Palmar Sur, mientras que los productores particulares nacionales cultivaban un total de 4.406 hectáreas en áreas ex bananeras ${ }^{19}$.

En la actualidad, el área perteneciente a la Compañía Bananera que se halla inscrita en el Registro Nacional se eleva a 5.420,8 hectáreas repartidas entre los cantones de

\footnotetext{
${ }^{17}$ La extensión cultivada estaba compuesta de 10.878 hectáreas de banano, 4.655 de cacao, 4.666 de palma, 1.296 de teca, 5.545 de potreros y 47 hectáreas en cultivos varios. Por otra parte, la Compañía tenía una extensión de 24.000 manzanas (16.783,2 hectáreas, 1 manzana=0,6993 hectáreas) arrendadas a 1.251 particulares. Rojas, Álvaro "La gran plantación bananera en Costa Rica”, MAG, Departamento de Planeamiento y Coordinación, s.f., p.18-19.

${ }_{18}$ En 1969 la United Fruit Company se fusionó con otras empresas para formar la United Brands. En 1990 United Brands cambió su nombre por el de Chiquita Brands International a donde pertenece Palma Tica.

${ }_{19}$ Compañía Palma Tica y Panamá. Plano General de Operaciones Palma Aceitera. Escala 1: 200.000, junio 1989. Barú Panamá, la filial panameña, cultivaba 2.516 hectáreas en tierras pertenecientes a la Chiriquí Land Company. A partir del mapa no podemos inferir si se trata de un proceso de recampesinización o bien una concentración productiva basada en grandes explotaciones.
} 
Quepos, Parrita, Osa, Golfito, Corredores, Siquirres y Limón. Por su parte, la United Fruit Company mantiene 751 hectáreas en el cantón de Limón ${ }^{20}$.

El cese de la actividad bananera en el Pacífico costarricense se debió en parte al incremento de los gastos de operación en Costa Rica y a los lineamientos estratégicos de United Brands, la corporación a la que pertenecía la UFCo. desde $1969^{21}$.

Por una parte, la infraestructura bananera requería un costoso mantenimiento y el precio del banano producido en Costa Rica había aumentado por efectos de la política estatal de fijación de un precio mínimo de comercialización. Además la Compañía no pudo beneficiarse de los subsidios estatales destinados a los productores locales puesto que su operación se basaba en la producción propia.

Por otra parte, la estrategia de United Brands era reducir el volumen productivo de alimentos en su facturación y en especial la producción bananera, máxime ante la sobreoferta de banano generada por sus empresas integrantes.

El Estado no supo anticipar el cese de las actividades y cuando la Compañía, aprovechando la huelga de 1984 decide el cierre de Palmar Sur, el país pasaba una crisis económica que restó capacidad negociadora al Estado ${ }^{22}$. En efecto, Costa Rica estaba recibiendo el rescate financiero estadounidense por lo que al Estado costarricense no le convenía enfrentar con dureza los intereses norteamericanos.

\section{Consideraciones finales}

La región del Pacífico sur costarricense se inscribe en un área de convergencia de poblaciones chiricanas de Panamá y costarricenses de la Meseta Central que desarrollaron una producción agrícola basada en el cultivo del arroz, el banano y los granos. La instalación de la United Fruit Company en la vertiente del Pacífico desde los años 1930 supuso una competencia por el control de las planas fluviales fértiles ya humanizadas y bajo cultivo.

El Estado costarricense, mediante los Contratos Bananeros y una política permisiva, sacrificó a los productores independientes y las posibilidades de un desarrollo autóctono permitiendo la absorción de aquéllos y el acaparamiento de las mejores tierras por parte de la Compañía. Sin embargo no se debe tanto a un criterio 'entreguista' como a la voluntad de poblar, comunicar y hacer producir el territorio bajo la intervención de capitales extranjeros ante la imposibilidad de lograr un impulso autóctono.

En su estrategia de implantación territorial, la Compañía Bananera discriminó entre las diferentes zonas del Pacífico costarricense. En la región del Pacífico central comprendida entre los valles de los ríos Parrita y Savegre, donde existían áreas cultivadas de banano explotadas por productores locales, la Compañía optó por la absorción de las fincas productores. Por su parte, en el Pacífico sur, en las zonas donde se presentaban mejores condiciones para el cultivo del banano, esto es las planas aluviales de los valles de los ríos Grande de Térraba, Esquinas y Coto Colorado, la Compañía emprendió una política de acaparamiento de tierras que a menudo vulneró los derechos de los ocupantes legítimos. Por fin, la implantación en la región fronteriza de

\footnotetext{
${ }^{20}$ En el Registro de la Propiedad aparecen 18 fincas que pertenecieron a la Bananera y que fueron vendidas 0 donadas al Estado en 1975, su área total suma 2.680,6 hectáreas. La superficie de las 51 fincas y lotes en manos de la Compañía se halla repartida esencialmente entre los cantones de Limón (1.632 has.), Quepos (1.213 has.), Osa (1.071 has.), Golfito (612 has.) y Parrita (519 has.). Sin embargo, no se pudieron obtener datos sobre el área bajo explotación de las empresas Numar S.A. y Palma Tica S.A. ambas pertenecientes al grupo Chiquita Brands. Estas empresas ocupan tierras que en su día pertenecieron a la Compañía Bananera de Costa Rica.

${ }^{21}$ Para mayor información sobre los cambios operados en el mercado bananero nacional y las verdaderas causas del abandono remitirse a Garnier, Leonardo y otros "Costa Rica: las vicisitudes de una política bananera nacional" pp. 99129 en "La economía bananera y las organizaciones de los trabajadores en la década de los ochenta en América latina" San José: Ediciones FLACSO / CEDAL / FES, 1988.

${ }^{22}$ Un análisis de la coyuntura económica de principios de los años 1980 se halla en Rovira Mas, Jorge "Costa Rica en los años 80" San José: Editorial Porvenir, 1987, pp. 62-95.
} 
Coto Colorado implicó compromisos con los dos países dentro de una lógica económica que trascendía las soberanías respectivas.

En el Pacífico sur se produjo un ordenamiento del territorio en función de la mata de banano. Las Divisiones, Distritos y Fincas se convirtieron en las unidades administrativas territoriales a falta de una mayor definición institucional del Estado costarricense. Se dotó a la región de un entramado de infraestructuras que respondían a la necesidad de comunicar la finca con el muelle y se crearon asentamientos humanos funcionales donde albergar a los trabajadores, sin olvidar la afluencia migratoria motivada por la oferta laboral que alteró los patrones de poblamiento hasta la actualidad. En general, se trató de un patrón planificado de colonización combinado con corrientes colonizadoras espontáneas en los márgenes de la explotación bananera.

La actividad bananera a lo largo del periodo comprendido entre 1938 y 1984 fue desplazándose hacia el Pacífico sur operándose una sustitución del banano por la palma aceitera en las tierras del Pacífico central. A la larga sería la solución preferida en todo el Pacífico según la estrategia de abandonar tierras agotadas y enfermas en lugar de invertir en su saneamiento. Al dedicar un mayor volumen de tierras al cultivo de la palma aceitera, primero en la División de Quepos y luego en la División de Golfito, en detrimento del cultivo del banano, se fue liberando mano de obra. Así se gestó la crisis laboral de los años 1980 que desembocó en invasiones precaristas y migraciones internas.

Como colofón, la contracción económica internacional de los años 1970 se alió a los cambios operados en el mercado bananero costarricense -entrada de nuevos competidores e impuestos a la exportación principalmente- además de los lineamientos de mercado de la United Brands a la que la UFCo. pertenecía y condujo al cese de la explotación bananera en Palmar Sur, el último distrito en operación, en 1984.

El cese de actividades abrió una crisis regional que aún no se ha cerrado. El Estado reaccionó ante las invasiones de fincas mediante el establecimiento de asentamientos campesinos gestionados por el Instituto de Desarrollo Agrario y con programas productivos financiados con fondos externos como los Proyectos Coto Sur y UNESUR (UNidad Ejecutora de la zona SUR) destinados a promover el cultivo de la palma africana en tierras ex bananeras.

Sin embargo estas medidas no lograron revertir los flujos migratorios de expulsión y la pauperización de los cantones comprendidos en el Pacífico sur costarricense ${ }^{23}$, donde las escasas fuentes de trabajo coexisten con fuertes volúmenes de Población en Edad Activa (PEA) fruto de las altas tasas de fecundidad y de inmigración acumulada ${ }^{24}$ de décadas anteriores.

\footnotetext{
${ }^{23}$ Según el Índice de Desarrollo Social (IDS), los cantones integrantes de la región del Pacífico sur costarricense, Osa, Golfito y Corredores, ocupan las posiciones 73,75 y 65 respectivamente sobre el total de 81 cantones del país. Entre 1984 y el 2000, estos cantones han retrocedido 8,4 y 5 posiciones respectivamente en la escala nacional. Los datos cantonales del IDS, también Ilamado Índice de Rezago Social, se hallan en González Quesada, Ma Elena "Índice de Rezago Social" San José: documento inédito, INEC, 2002, Anexo 1, p.26. http://www.inec.go.cr

${ }^{24}$ La Población en Edad Activa (PEA) del cantón Osa en el 2000 representa el 66,68\% de la población total, fruto de las altas tasas de fecundidad (incrementadas por la inmigración de mujeres de edades comprendidas entre los 12-34 años) y la inmigración acumulada (principalmente masculina según revelan los índices de masculinidad de los grupos etarios mayores) patente a la vista de los saldos migratorios netos de $1950(50,96 \%)$ y $1963(25,24 \%)$. Censos de población 1950, 1963, 2000, DGEC.
} 


\section{BIBLIOGRAFÍA}

Camacho Nassar, Carlos "En la frontera del siglo XX. La exclusión de los guaymíes en Costa Rica" San José: Escuela de Antropología y Sociología, Universidad de Costa Rica, 1996.

Carcanholo, Reinaldo "Sobre la evolución de las actividades en Costa Rica" pp.143-203 en Estudios Sociales Centroamericanos, n¹9, 1978.

Cerdas Albertazzi, Ana Luisa "El surgimiento del enclave bananero en el Pacífico Sur" pp.117-159 en Revista de Historia, ${ }^{\circ}$ 28, julio-diciembre 1993.

Colectivo "Panamá y la Frutera. Análisis de una confrontación económico-fiscal" Panamá: Imprenta Universitaria, 1974. Contreras Solís, Fernando "Evolución histórica del enclave bananero en Costa Rica" Tesis de Licenciatura en Historia, Universidad de Costa Rica, 1974.

Ellis, Frank "Las transnacionales del banano" San José: EDUCA, 1983.

García, Manuel "Apuntes geohistóricos de la colonización agrícola en la Península de Osa, Costa Rica” pp.27-40 en Geoistmo, Vol.II, $n^{\circ} 1,1988$.

Hall, Carolyn "Costa Rica, una interpretación geográfica con perspectiva histórica" San José: Editorial Costa Rica, 1984.

Heilbron, Armando y otros "La United Fruit Company y su trascendencia en el país", Universidad de Costa Rica, Cátedra de Estudios Generales, 1979, p. 127.

Jones, F. Clarence y Morrison, Paul "Evolution of the banana industry of Costa Rica" pp.1-19 en Economic Geography, volumen 28, n 1 , enero 1952.

Kepner, Charles y Soothill, J.H. "El imperio del banano. Las compañías bananeras contra la soberanía de las naciones del Caribe", Ediciones del Caribe, México, 1949.

Lewis, Barbara "Reseña histórica de la población y los recursos naturales de la Península de Osa, Pacífico Sur, 1848-1981” pp.123-130 en Revista Geográfica de América Central, $n^{\circ} 17-18,1982-1983$.

Plaza, Galo y May, Stacy "La United Fruit Company en América Latina" México: Imprenta Nuevo Mundo-National Planning Association, 1958.

Rojas, Álvaro "La gran plantación bananera en Costa Rica", MAG, Departamento de Planeamiento y Coordinación, s.f.

Sandner, Gerhard "El concepto espacial y los sistemas funcionales en la colonización espontánea costarricense” San José: MOPT-Instituto Geográfico de Costa Rica, 1963.

"La colonización agrícola de Costa Rica" San José: Instituto Geográfico Nacional, Tomo I, 1964.

Stouse, JR "Cambios en el uso de la tierra en regiones ex bananeras de Costa Rica" Ministerio de Transportes, Instituto Geográfico Nacional, 1967.

Viales Hurtado, Ronny "Los liberales y la colonización de las áreas de frontera no cafetaleras: el caso de la región Atlántica (Caribe) costarricense entre 1870 y 1930", Tesis de doctorado, Universitat Autònoma de Barcelona, 2000. 